\title{
The Analysis of Spatial-Temporal Evolution of City Accessibility Based on Highway Network in Henan Province in China
}

\author{
Mingting Ba, Hongling Meng, Kaiguang Zhang, Yanmin Sun \\ School of Geography and Tourism, Zhengzhou Normal University, Zhengzhou, China \\ Email: zzgis@zznu.edu.cn
}

How to cite this paper: Ba, M.T., Meng, H.L., Zhang, K.G. and Sun, Y.M. (2021) The Analysis of Spatial-Temporal Evolution of City Accessibility Based on Highway Network in Henan Province in China. Journal of Transportation Technologies, 11, 296310.

https://doi.org/10.4236/jtts.2021.112019

Received: March 17, 2021

Accepted: April 26, 2021

Published: April 29, 2021

Copyright $\odot 2021$ by author(s) and Scientific Research Publishing Inc. This work is licensed under the Creative Commons Attribution International License (CC BY 4.0).

http://creativecommons.org/licenses/by/4.0/

\begin{abstract}
Accessibility is an important tool to evaluate the maturity of a regional traffic network structure which describes the traffic convenience in the traffic network. The paper defines a new accessibility index by using the resident population weighted average value of the sum of inverse of the traveling time distance and time threshold coming from ordinary traffic network, and then uses this accessibility index to analyze the spatial-temporal characteristics of Henan highway network, as well as its evolution patterns from 2005 to 2020. The results show that with the expansion and improvement of Henan highway network, city accessibility level has been significantly improved, spatial convergence is obvious, the cities in the north central are always High-High aggregation area, the cities in the south are always Low-Low aggregation area, gradually forming the characteristics of Northwest high and Southeast low, relative balance between East and West. There is some non-conforming phenomenon in highway mileage growth and improvement of the city accessibility levels, but this situation is being weakened, the highway network layout is gradually rationalized, the spatial distribution of city accessibility and that of population are beginning to converge.
\end{abstract}

\section{Keywords}

Highway Network, Accessibility, Inverse of Time Distance, Spatial

Distribution, Spatial-Temporal Evolution, Spatial Aggregation,

Henan Province

\section{Introduction}

Transportation is the basic industry of national economy, which is closely related to regional economic and social development. Highway traffic system is an 
important symbol of transportation modernization, forming a regional vascular and lifeline. An excellent highway system not only could effectively improve the regional logistics level, shortens the distance between cities, but also provides the fundamental guarantee for regional economic balanced development and promoting regional economic integration [1]. Therefore, the evolving pattern research of regional highway traffic system is of great significance to appraise the status and tendencies of regional economic development. In modern location theory, accessibility index is an important index to evaluate the perfectness of a traffic network, which mainly describes the ability of interaction between nodes and the convenience of traffic among nodes in the traffic network [2] [3].

At present, the accessibility studies mainly concentrate on the accessibility distribution status, and its evolution characteristics analysis, the impact on regional economic development, at the same time, introduce the fractal theory, network theory, syntax, shortest path and spatial topology to structure accessibility factors reflecting the different network characteristics, and have obtained some valuable results, but the research object is mainly for simple traffic network, the research measure use Euclidean distance, the changes of measure values are seriously affect the reliability of the analysis results [4] [5] [6] [7] [8].

With the rapid development of regional economy, regional traffic system is becoming pluralistic. The research on the spatial-temporal evolution characteristics of city accessibility level could effectively evaluate the perfectness of highway traffic network, and provide scientific reference for constructing a mature highspeed traffic system.

This paper defines a new Accessibility index by using the resident population weighted average value of the sum of inverse of the traveling time distance and time threshold coming from ordinary traffic network. Using this accessibility index, this paper evenly divides the 15 years (early 2005-early 2020) into 3 time stages, and on 4 time sections to study the impact of highway constructions on city accessibility, explore its spatial-temporal characteristics and evolution patterns, as well as the spatial relationship between city accessibility and city population change.

\section{Data and Research Methods}

\subsection{Data}

The operation of the first highway line, Lankao to Luoyang section of Lianhuo national highways in 1995, marks Henan traffic is run into high-speed traffic era. Since 2005, along with the province's economic strength has grown, the province's highway network has been rapid developed, has implemented "2006 Henan Province Highway Plan" and "2009 Henan Province Highway Adjustment Plan". By the end of 2020, the highway mileage is up to $7100 \mathrm{~km}$, basically forms an excellent highway traffic network with 12 national highways and 30 provincial highway in the province.

The spatial data of the study are from the Henan highway spatial database and meta-database. The time distance is based on the weighted average of the empir- 
ical traveling time on lines and intersections in traffic network from the corresponding years. The time shortest distance between cities is calculated by NEDS algorithm [9] [10]. The resident population data are from Henan Province Statistical Yearbook.

\subsection{Accessibility Index}

The city accessibility index is a description of the traffic convenience degree from all adjacent cities to the city [1] [5] [6]. There are various possibilities in direct connections and circuitous connections between two adjacent cities in the highway traffic network. The study of city accessibility coming from highway traffic network only use the traffic routes within the time threshold defined before, usually the time threshold is set as the shortest travel time between cities on the ordinary traffic network. Two routes are considered to be the same if and only if their route repetition rate is greater than $50 \%$.

The city accessibility index is defined as the resident population weighted average of the inverse of time distance, the use of the inverse could greatly reduce the influence of numerical value on the analysis results [10].

The city $i$ accessibility from city $j(j \rightarrow i)$ is defined as the sum of the inverse of time distance $\left(T_{k}^{-1}\right)$ from city $j$ to city $i$ for all routes $(r)$, on which the traveling time are less than the time threshold, and do not travel through the third city, denoted as $A_{i j}$, the larger $A_{i j}$ means better traffic convenience degree from city $j$ to city $i$, sometimes $A_{i j} \neq A_{j i}$.

$$
A_{i j}=\sum_{k=1}^{r} T_{r}^{-1}
$$

The city $i$ accessibility index $A_{i}$ is defined as the resident population weighted average of accessibility from all adjacent cities in the region,

$$
A_{i}=\frac{1}{\sum_{j=1}^{r} M_{j}} \sum_{j=1}^{r} M_{j} A_{i j},
$$

where, $M_{j}$ is the resident population of the city $j$, which indicates the influence degree of $j$ on the city $i$ accessibilities. The larger $A_{i}$ means the better traffic convenience degree from all adjacent cities to city $i$.

\subsection{Spatial Auto-Correlation Analysis}

The spatial auto-correlation analysis is based on Moran's I, which describes the spatial correlation patterns at different spatial positions, reflects the spatial difference and similarity degrees for the adjacent regions with a certain regular distribution samples [11].

The global spatial autocorrelation index (Global Moran's I) is defined as:

$$
I=\frac{\sum_{i=1}^{n} \sum_{j=1}^{n} w_{i j}\left(A_{i}-\bar{A}\right)\left(A_{j}-\bar{A}\right)}{S^{2} \sum_{i=1}^{n} \sum_{j \neq i}^{n} w_{i j}},
$$

where $A_{i}$ is the accessibility level of city $i,\left(w_{i j}\right)$ is the spatial relation weight matrix, $w_{i j}=1$ if city $i$ and $j$ have more than one common border, otherwise 
$w_{i j}=0, \bar{A}$ and $S^{2}$ respectively are the mean and the variance of the accessibility level in the study region.

The value range of Global Moran's I belongs to $[-1,1], I>0$ indicates that the city accessibility shows the characteristics of aggregation, most of cities and their adjacent cities have the same difference direction with the accessibility mean of the region, the larger $I$ means the more obvious aggregating tendency; $I<0$ indicates that the city accessibility is dispersed, some of cities and their adjacent cities have the different variety direction with the accessibility mean of the region [11] [12]. The smaller $|I|$ means the more obvious decentralizing tendency; $I=0$ means that the city accessibility in the region is randomly distributed, no autocorrelation existing among them. Assessing the correlation using the standardized $Z$,

$$
Z=\frac{I-E(I)}{\sqrt{\operatorname{VAR}(I)}},
$$

as the test statistic, where $E(I), \operatorname{VAR}(I)$ respectively are the mean and the variance of $I$, calculated by the number of cities and the spatial relation weight matrix $\left(w_{i j}\right)$, under the hypothesis of $I$ is a normal distribution, its critical value is 1.65 under the confidence level of 95\% [13] [14].

Global Moran's I is a global assessment of spatial autocorrelation, ignoring the potential instability of spatial distribution. Local autocorrelation index is used to measure the influence degree of local spatial units to the overall spatial autocorrelation in the study region, and to what extent the global assessment of spatial autocorrelation masks abnormal local conditions or small local instability.

The local spatial autocorrelation index (LISA) is defined as

$$
I_{i}=\frac{\left(x_{i}-\bar{x}\right) \sum_{j \neq i}^{n} w_{i j}\left(x_{j}-\bar{x}\right)}{S^{2}},
$$

$I_{i}$ describes the spatial aggregation degree between city $i$ and its adjacent cities with significant similar values.

The local spatial autocorrelation index decomposes the global spatial autocorrelation index into the contributions of each city, $I_{i}>0$ means city $i$ have the same deviation direction with most of its adjacent cities about the accessibility mean of the region, the local region with the center of city $i$ presents a high-high $(\mathrm{HH})$ or low-low (LL) aggregation feature. $I_{i}<0$ means city $i$ have the different deviation direction with most of its adjacent cities, the local region with the center of city $i$ presents low-value surrounded by high-value (LH) or high-value surrounded by low-value cities (HL), the local region with the center of city $i$ presents some decentralization feature [11] [12] [13].

\subsection{Centralization Analysis}

The city accessibilities coming from highway traffic network in a region have some correlations with the location of cities and the weighted parameters. The accessibility of one city reflects its centrality degree in the region, and the con- 
venience degree the people of adjacent cities traveling to it. The center of accessibility $B_{0}$ in a region is defined as the weighted average of city geographical coordinates with its Accessibility as weight. The center of population $R_{0}$ is defined as the weighted average of city geographical coordinates with the number of resident population as weight.

$$
\begin{aligned}
B_{0} & =\left(\frac{A_{i}}{\sum A_{i}} x_{i}, \frac{A_{i}}{\sum A_{i}} y_{i}\right) \\
R_{0} & =\left(\frac{m_{i}}{\sum M_{i}} x_{i}, \frac{m_{i}}{\sum M_{i}} y_{i}\right)
\end{aligned}
$$

where $\left(x_{i}, y_{i}\right)$ represents the geographical coordinates of the city $i$.

\section{Spatial-Temporal Characteristics of the City Accessibilities in Henan Province}

\subsection{Spatial-Temporal Characteristics of Highway Traffic Network in Henan Province}

Henan highway traffic network has gotten considerable development in the 15 years from 2005 to 2020 (Figure 1 and Figure 2), the traffic mileage has increased from $1940 \mathrm{~km}$ in 2005 to 7100 in 2020, increased nearly 3 times, of which the first stage is the fastest growing stage to reach $57 \%$, followed by the second stage as $22 \%$, and the third stage as $19 \%$. The $2.5 \mathrm{~h}$ city traffic circle with Zhengzhou as the centre has been forming in the region.

\subsection{Spatial Distribution Characteristics of City Accessibilities in Henan Province}

The city accessibilities on each time section in Henan Province are calculated by using the formulas (1) and (2), the corresponding time thresholds and the resident population data. The results are shown in Table 1. For each time section, using spatial clustering analysis, divided the city accessibilities into 4 grades, as excellent, good, moderate, and poor, the results are showed in Figure 3 and Figure 4.

\begin{tabular}{|c|c|c|c|c|c|c|c|c|c|c|}
\hline Year & AnYang & $\mathrm{HeBi}$ & JiYuan & JiaoZuo & KaiFeng & ShangQiu & SanMenXia & PingDingSan & NanYang & PuYang \\
\hline 2005 & 0.53 & 0.63 & 0.74 & 1.08 & 0.98 & 0.46 & 0.51 & 0.41 & 0.21 & 0.33 \\
\hline 2010 & 0.96 & 1.40 & 1.11 & 1.77 & 1.44 & 0.89 & 0.68 & 1.08 & 0.69 & 0.69 \\
\hline 2015 & 1.21 & 1.66 & 2.03 & 1.79 & 1.65 & 1.13 & 0.73 & 1.04 & 0.69 & 0.87 \\
\hline 2020 & 2.25 & 2.30 & 2.19 & 2.06 & 2.10 & 1.30 & 0.88 & 1.09 & 0.74 & 1.02 \\
\hline 2005 & 0.74 & 0.53 & 0.43 & 0.85 & 0.43 & 0.37 & 0.42 & 1.14 & 0.38 & 2.29 \\
\hline 2010 & 1.12 & 1.61 & 1.25 & 1.52 & 0.77 & 0.91 & 0.82 & 1.58 & 0.25 & 1.68 \\
\hline 2015 & 1.06 & 1.59 & 1.40 & 1.57 & 0.74 & 1.23 & 1.02 & 1.59 & 0.31 & 2.08 \\
\hline 2020 & 1.31 & 1.82 & 1.59 & 1.63 & 0.78 & 1.40 & 1.07 & 1.60 & 0.21 & 1.65 \\
\hline
\end{tabular}

Table 1. The city accessibilities in Henan province from 2005 to 2020. 


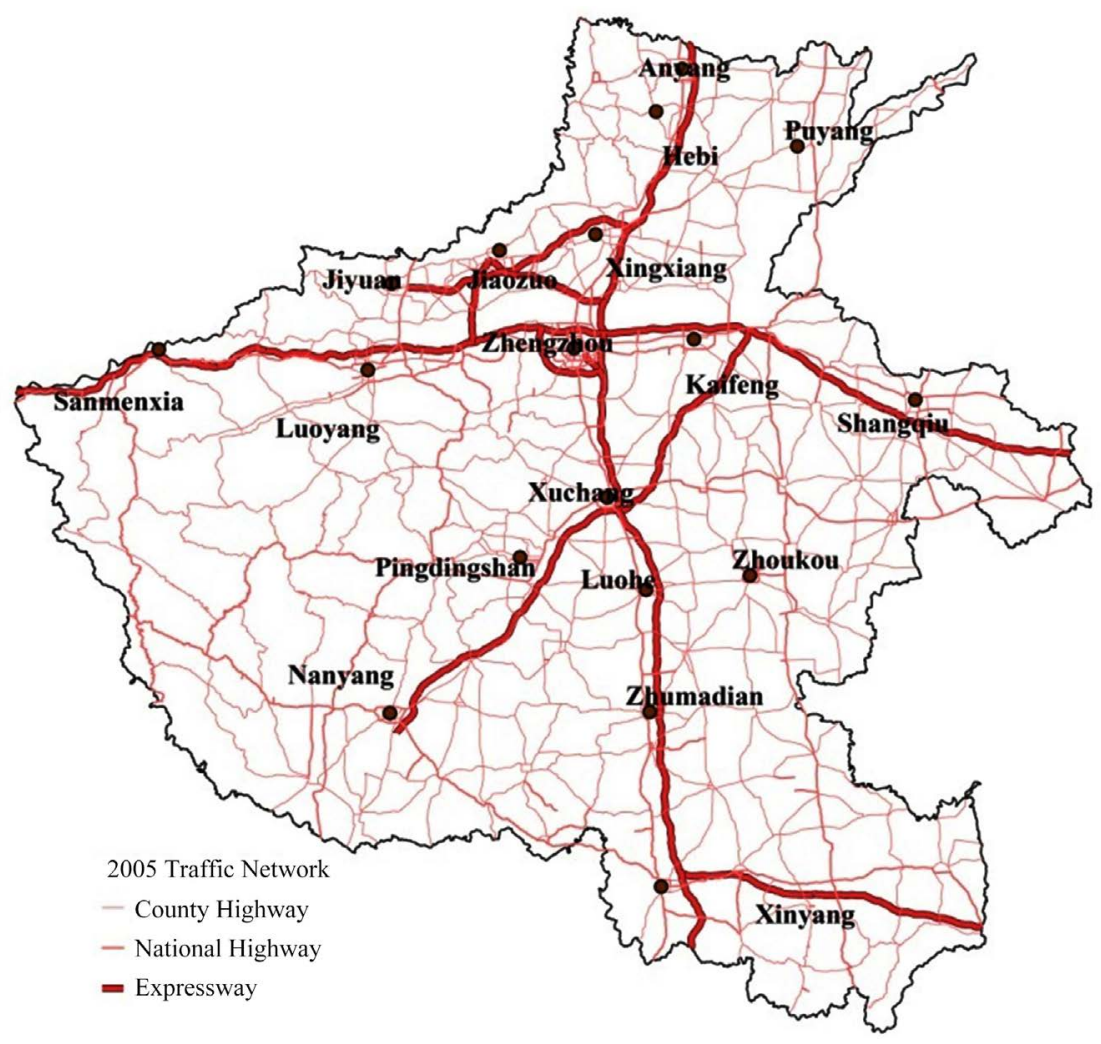

2005

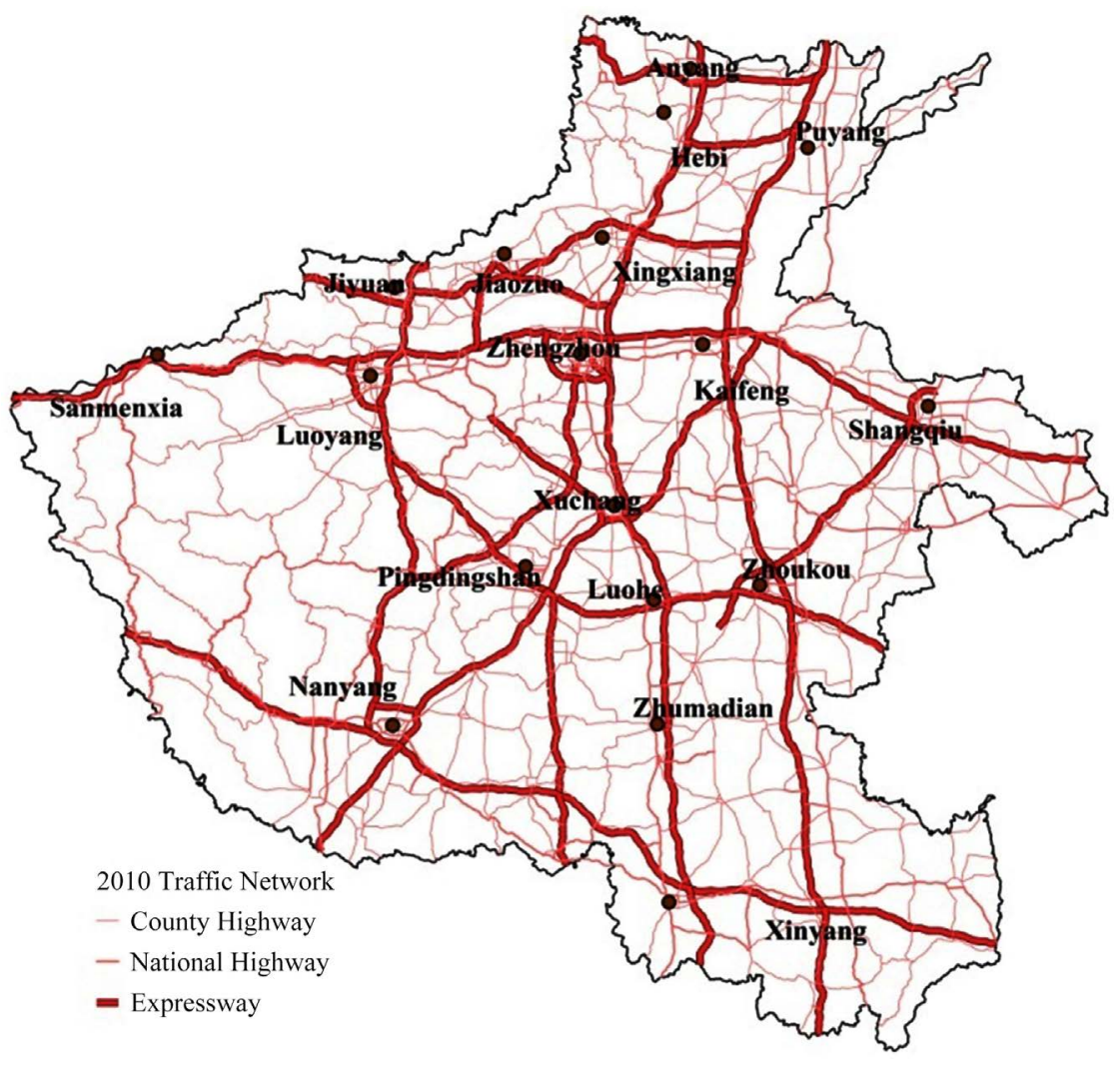

2010

Figure 1. The traffic network of Henan from 2005 to 2010. 


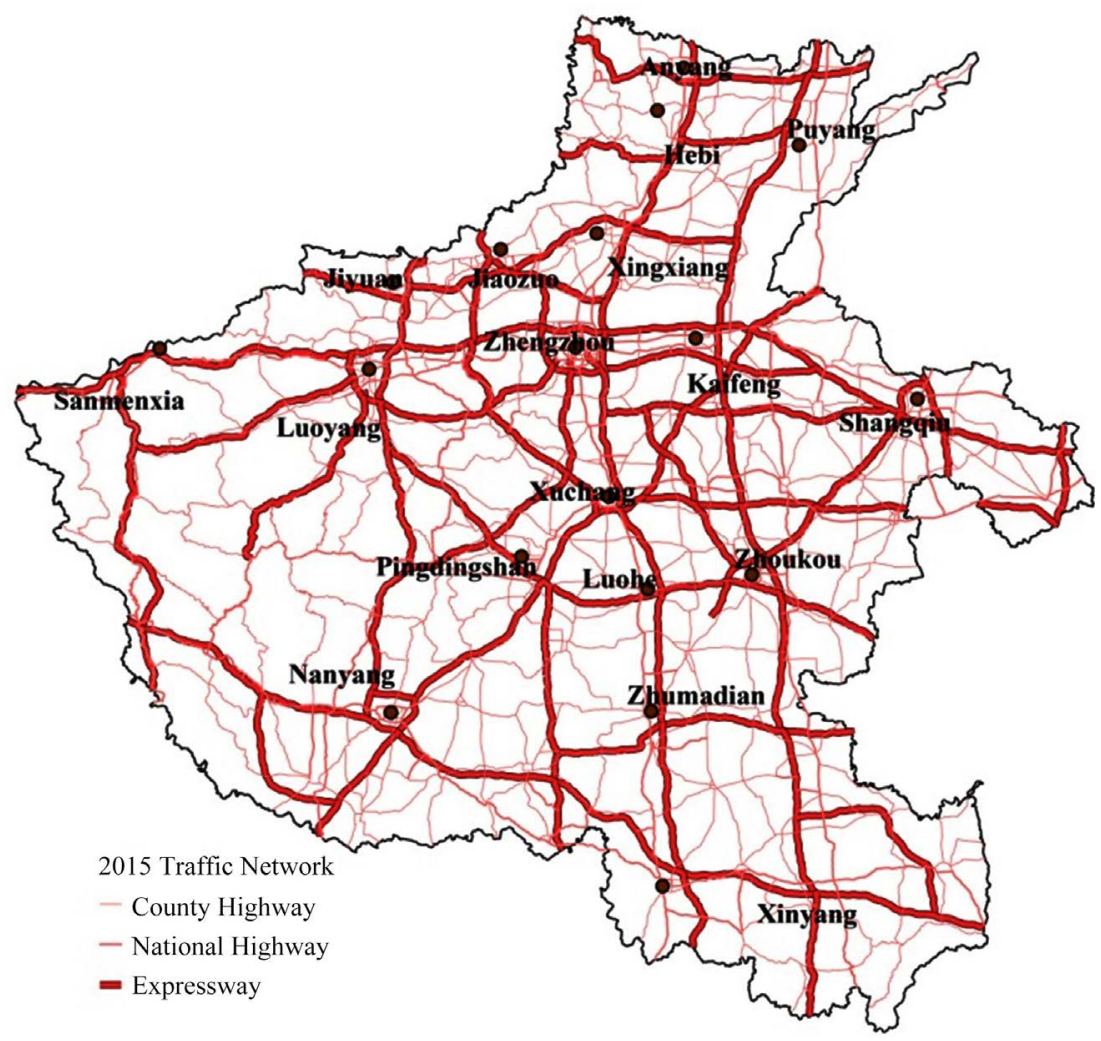

2015

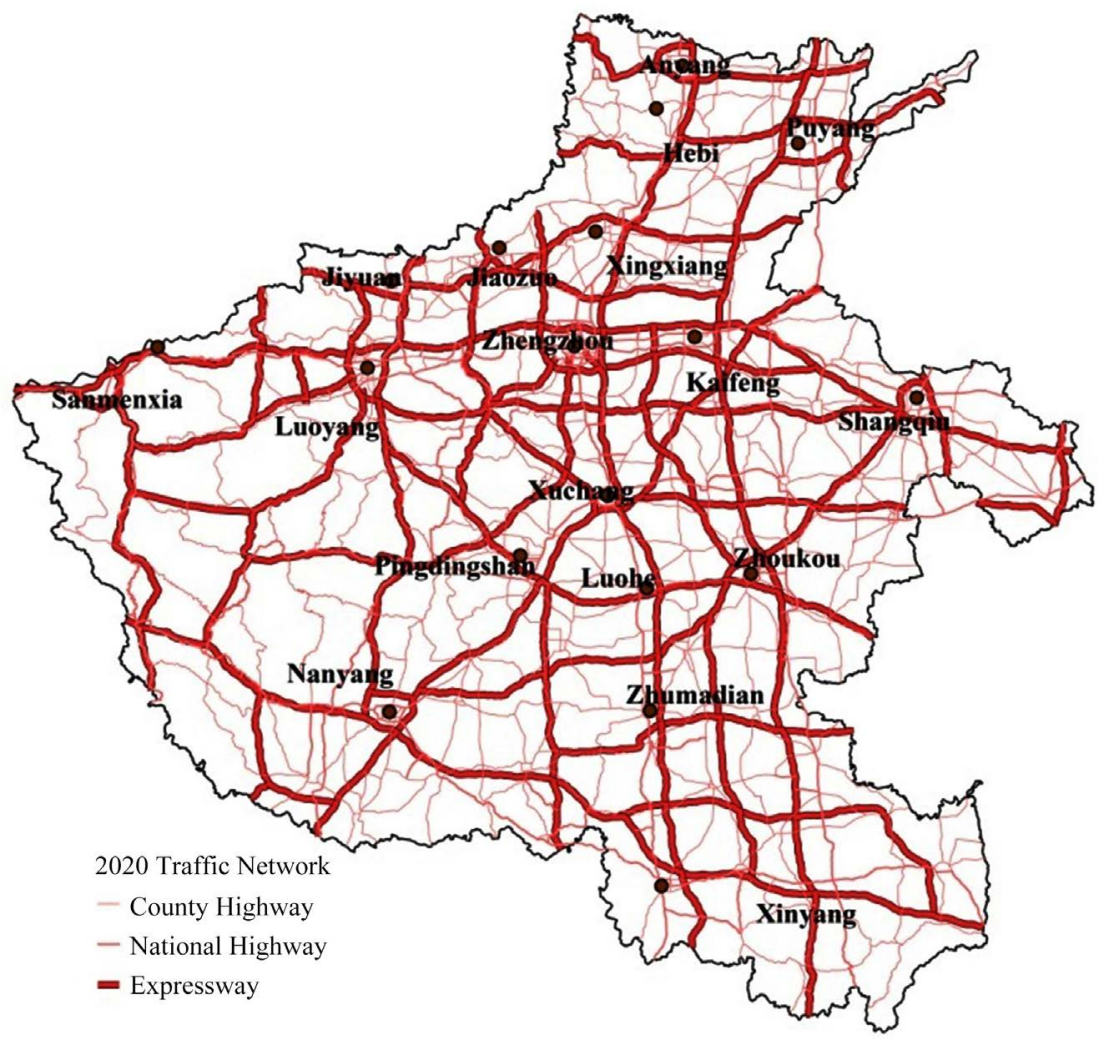

2020

Figure 2. The traffic network of Henan from 2015 to 2020. 

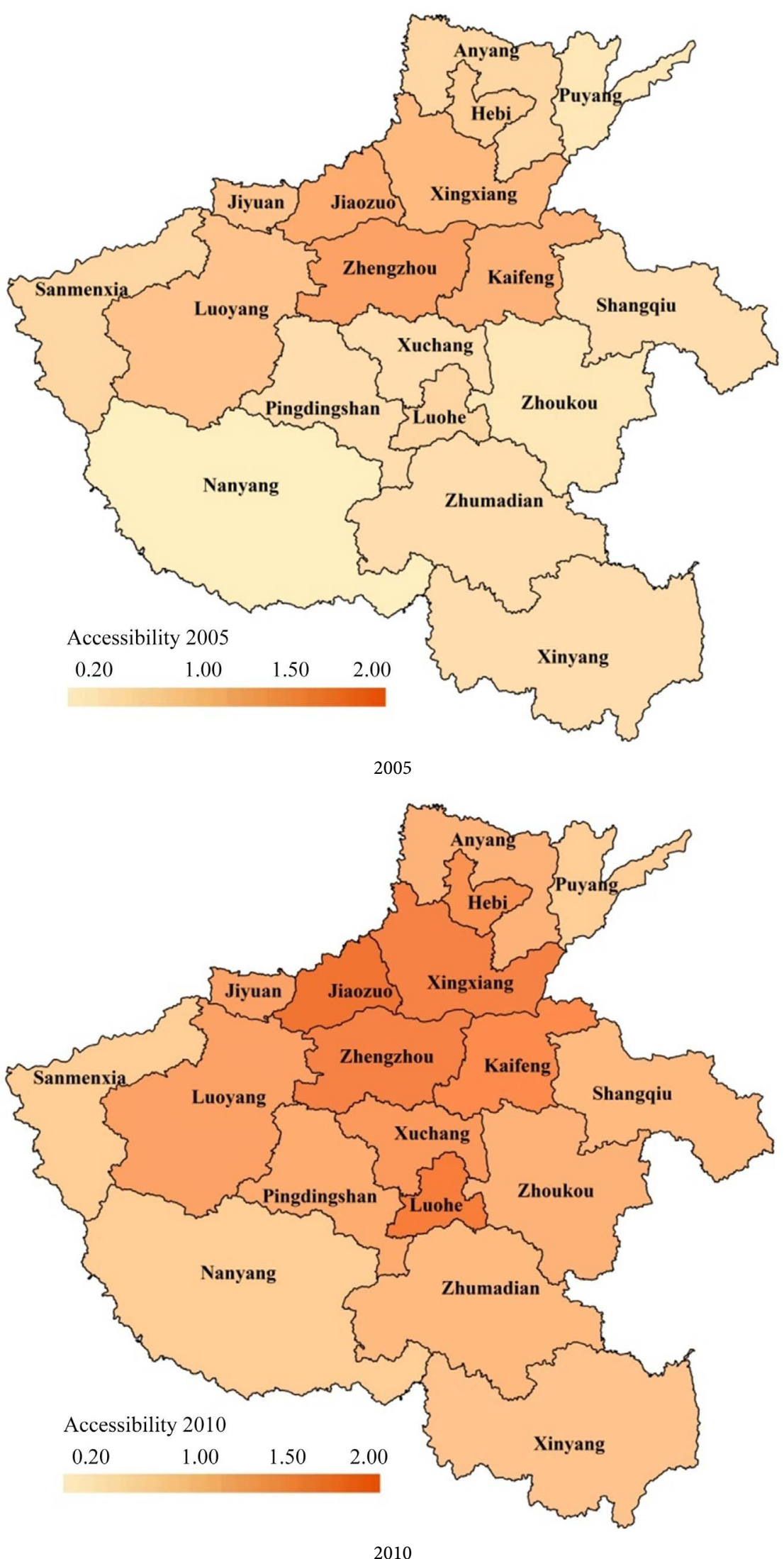

Figure 3. The spatial distribution of city accessibility from 2005 to 2010. 



2020

Figure 4. The spatial distribution of city accessibility from 2015 to 2020. 
On four time sections, Jiaozuo and Kaifeng accessibilities are always in the excellent group, they are tourism-oriented cities, in order to attract tourists, the local governments increase the construction of transport facilities, have completed a number of highway construction in the different time stages, constitute a radioactive traffic network.

On the first two time sections, Zhengzhou accessibilities are in the excellent group, and on the latter two time sections are in the good group, that is for the city accessibility level not only reflects the distribution of highway traffic network in the city region, but also is affected by its spatial geographical position in the highway traffic network and the city resident population of its adjacent cities. The operations of S88 in 2009 and S25 in 2015 make the direct linkage range respectively extend to Pingdingshan and Zhoukou.

On four time sections, Sanmenxia, Nanyang, Xinyang and Puyang always have poor accessibility levels, their common features are located on the periphery of the province, have relatively complex terrain and low population density.

\subsection{Spatial Aggregation Characteristics of City Accessibilities in Henan Province}

Using the formulas (3), (4) and (5) calculate the global spatial autocorrelation indices and the local spatial autocorrelation indices, as well as the corresponding $Z$ values, the results are showed in Table 1 and Figure 5 and Figure 6.

Under the confidence level of $95 \%$, the city accessibilities display significant spatial aggregation characteristics in the four time sections, Global Moran'I and significant levels gradually reduce.

The HH aggregation cities are always located around Zhengzhouon, the provincial capital. The LL aggregation cities are located in the south of the province. There are no HL and LH aggregation cities. On the first time section, the $\mathrm{HH}$ aggregation cities are Xinxiang, jiaozuo and Zhengzhou, the LL aggregation cities are Luohe, Zhumadian and Xinyang. On the second time section, Zhengzhou is $\mathrm{HH}$ aggregation city, the LL aggregation cities are Nanyang and Xinyang. On the third time section, Jiaozuo is HH aggregation city, the LL aggregation cities are Sanmenxia, Nanyang, Zhumadian and Xinyang. On the fourth section, Xinxiang is the $\mathrm{HH}$ aggregation city, the LL aggregation cities are Nanyang, Zhumadian and Xinyang.

\subsection{The Center Distribution Characteristics of City Accessibility Centers in Henan Highway}

Using the formulas (6) and (7) to calculate the city accessibility centers and resident population centers at each time section, the results are showed in Figure 7. With the development of urbanization, the population agglomeration in Zhengzhou is becoming more and more obvious. The resident population center is continuously moving to the northwest. But in the three stages, the aggregation speed gradually decreases.

There are significant differences between the movement of accessibility centers 

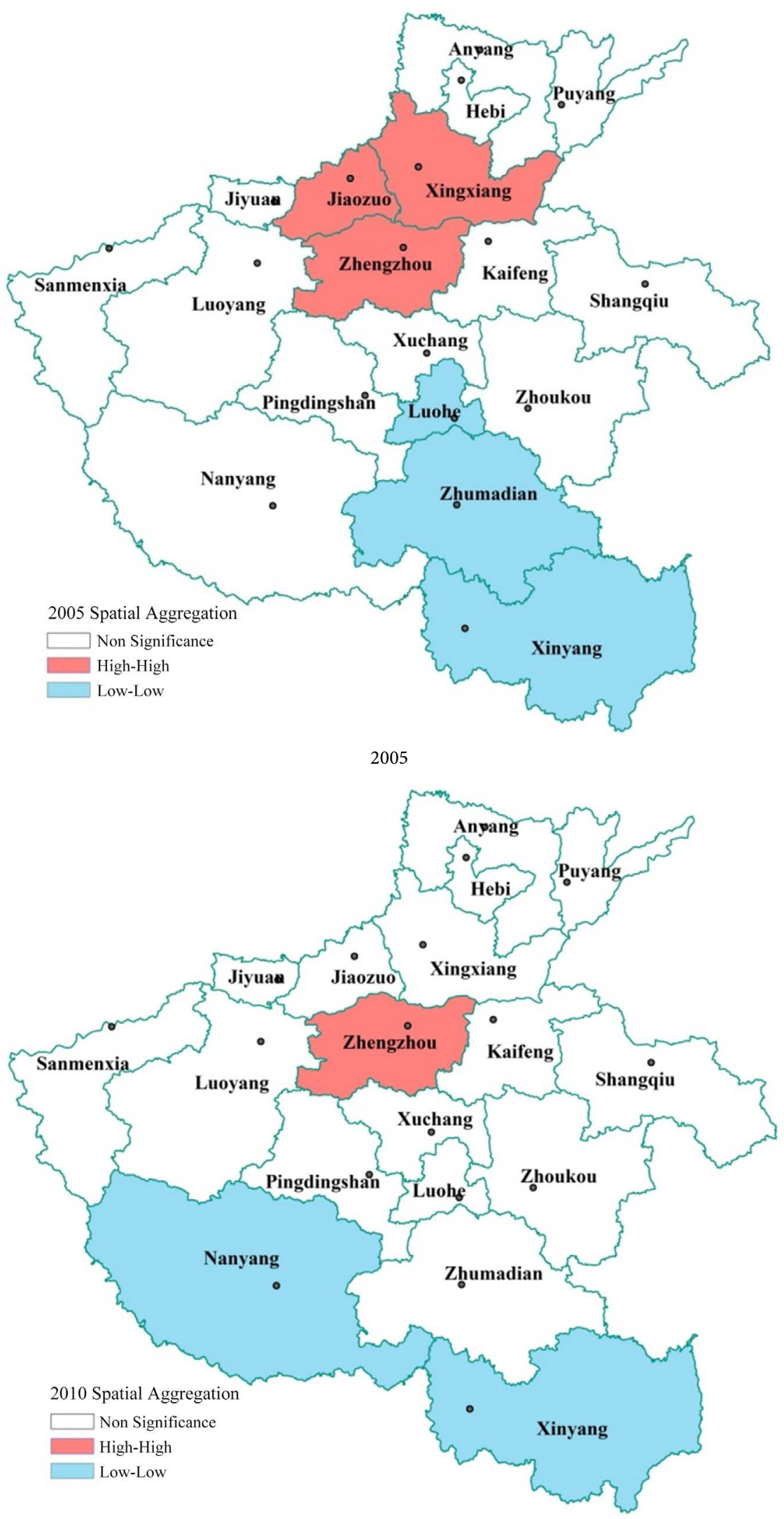

2010

Figure 5. The spatial aggregation distributions of city accessibility from 2005 to 2010. 

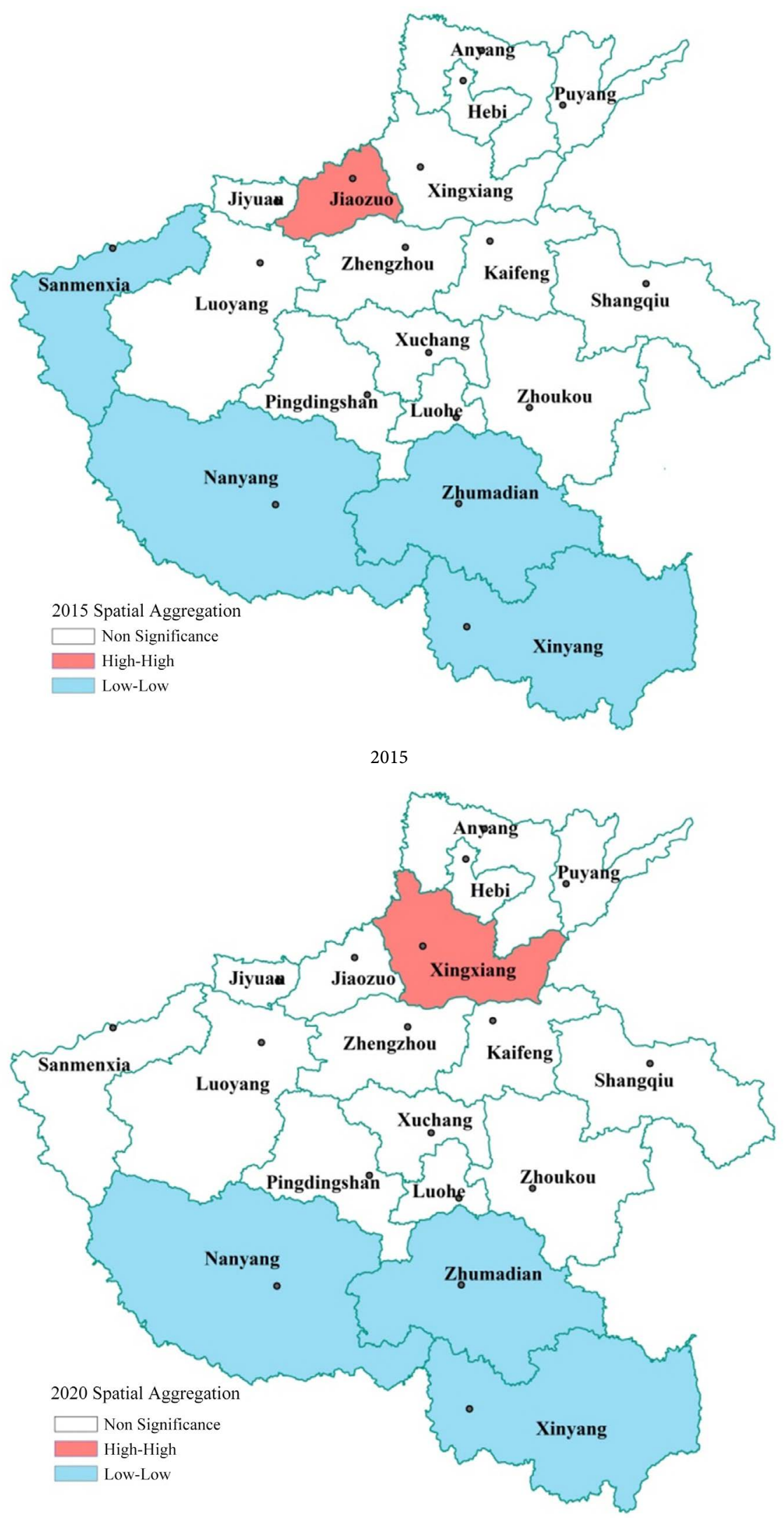

2020

Figure 6. The spatial aggregation distributions of city accessibility from 2015 to 2020 . 


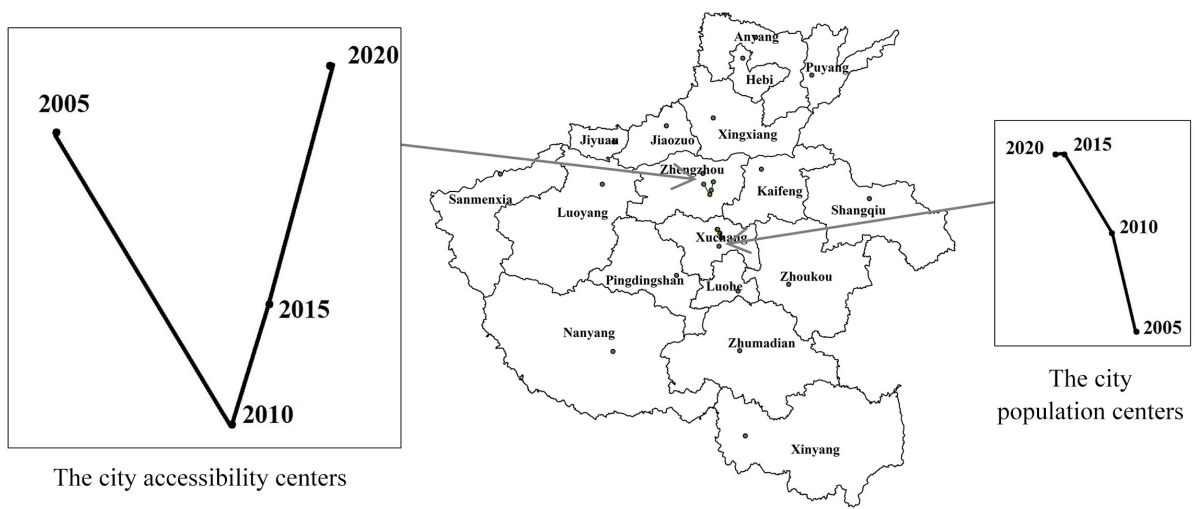

Figure 7. The spatial distributions of city accessibility and population centers from 2005 to 2020 .

and the resident population centers.

In the first stage, the rapid development of the highway traffic network in the central and southern regions makes the city accessibility center move $15 \mathrm{~km}$ to the southeast. In the second and the third stages, due to lots of provincial highway construction in the central and northern regions, the city accessibility center gradually move to Zhengzhou along the northwest direction, the moving speed is significantly faster in the third stage than that in the second stage.

The distance between the city accessibility center and the resident population center is gradually reduced. On the one hand, it shows that the construction of highway network in the whole province improves the level of city accessibility, has effectively promoted the process of population circulation and urbanization. On the other hand, it also shows that the highway network is gradually rationalized.

\subsection{Analysis on the Spatial Evolution Causes of City Accessibility in Henan Province}

The city Accessibilities shows a core-periphery feature, centered on the provincial capital Zhengzhou, from 2015 and 2020, this feature is weakening.

From 2005 to 2020, the accessibility level of each city has been improved to a certain extent the average value gradually increases, but the standard deviation also becomes larger.

There is some non-conforming phenomenon in highway mileage growth and improvement of the city accessibility levels, which indicates that although the highway construction has developed rapidly, there are some irrationalities in the network layout.

From 2005 to 2010, with Erguang highway, Daguang highway, Hushan highway, Ningluo highway, Shangnan highway (Shangqiu-Zhoukou) and Zhengrao highway (Zhengzou-Pingdingshan) completed and opened to traffic, the highway mileage increases from $1940 \mathrm{~km}$ to $4487 \mathrm{~km}$, the accessibility of cities in the central and southern parts of the province, as Nanyang, Luohe, Xuchang, Pingdingshan and Zhoukou, has been greatly improved. 
From 2010 to 2015, the highway mileage increases to $6373 \mathrm{~km}$, with the construction of Zhengmin highway, Shangdeng highway (Zhengzhou-Shangqiu), Yanluo highway, Jixi highway and Xinyang highway, the accessibility of cities in the eastern cities, as Shangqiu and Zhoukou, have increased rapidly.

From 2010 to 2020, the highway mileage increased to $7100 \mathrm{~km}$, the construction emphasis is on the encryption of the original highway network and the construction of highways in peripheral areas. With Shangnan highway (Zhoukounanyang), Taihui highway, Jiaotong highway (Gongyi-Pingdingshan) and Huinei highway have bulit successively, the accessibility of cities, as Zhoukou, Nanyang, Pingdingshan and Puyang have been improved to a certain extent.

\section{Conclusions}

The paper defines a new accessibility index by using the resident population weighted average value of the sum of inverse of the traveling time distance and time threshold coming from ordinary traffic network, and uses this accessibility index to analyze the spatial-temporal characteristics of Henan highway network, as well as its evolution patterns from 2005 to 2020. The research shows that:

From 2005, as the expanding and perfecting of Henan highway traffic network, the city accessibility levels have been effectively improved, but produce obvious spatial convergence characteristics, the cities in the north central are always HighHigh aggregation area, the cities in the south are always Low-Low aggregation area, gradually forming the characteristics of Northwest high and Southeast low, relative balance between East and West.

As the construction of highway traffic network has the stage characteristics, the evolution characteristics of city accessibilities have obviously differences in the different stages. The optimization degree of city accessibilities in the first stage is obviously higher than that of in the second and third stages. The degrees of improvement of the periphery cities are always higher than that of the other cities.

There is some non-conforming phenomenon in highway mileage growth and improvement of the city accessibility levels, but this situation is being weakened, the highway network layout is gradually rationalized, the spatial distribution of city accessibility and that of population are beginning to converge.

This accessibility index effectively reduces the numerical effect of the measurement data on the analysis result, the calculation process is simple and reliable. When a highway opens to traffic, it is only necessary to calculate the accessibility of its connected city and their surrounding city, and other areas would not be affected. in the future, it should be used widely to research the rational layout of network, such as high-speed railway, logistics distribution network, etc.

\section{Conflicts of Interest}

The authors declare no conflicts of interest regarding the publication of this paper. 


\section{References}

[1] Yin, Z.C., Jin, Z.H.N., Ying, S., et al. (2020) A Spatial Data Model for Urban Spatial-Temporal Accessibility Analysis. Journal of Geographical Systems, 22, 447-468. https://doi.org/10.1007/s10109-020-00330-6

[2] Li, B.J., Gu, H.H. and Ji, Y.Z. (2012) A Study on Accessibility of Transportation Infrastructure in Urban and Rural Area of Xuzou Based on GIS. Human Geography, 6, 76-80.

[3] Henrike, R. and Amaya, V. (2012) Spatial (Im)mobility and Accessibility in Ireland: Implications for Transport Policy . Growth and Change, 43, 667-696. https://doi.org/10.1111/j.1468-2257.2012.00602.x

[4] Sheng, J.H., Lu, Y.Q. and Lan, X.J. (2012) Assessment on Accessibility of Regional Comprehensive Transport: A Case Study of Anhui. Geographical Research, 31, 1280 1293.

[5] Xiao, J.G. and Zhou, T.G. (2015) Spatial-Temporal Characteristics of Chongqing Transport Network Accessibility and Its Evolution Pattern. Journal of Geo-Information Science, 17, 54-61.

[6] Li, H., Li, X.Y. and Wu, C.G. (2011) Study on Highway Accessibility and Spatial Layout Alteration of Central China Urban Agglomeration. Areal Research and Development, 30, 55-58.

[7] Li, Q.H. and Wang, X.Y. (2013) Research on the Public Transportation Accessibility in Lhasa. Journal of Tibet University, 28, 117-120.

[8] Jiang, X.W., Cao, W.D. and Luo, J. (2012) Spatial Pattern and Evolution of Road Network Accessibility in Anhui Province. Progress in Geography, 31, 1591-1599.

[9] Zhang, K.G., Meng, H.L., Ba, M.T., et al. (2013) The Research on Optimum Route Algorithm in Non-Euclidean Distance Space. Journal of Geomatics Science and Technology, 30, 83-86.

[10] Zhang, K.G., Shi, Y. and Ba, M.T. (2014) The Spatial Distribution Analysis on Highway Serving Area in Henan Province. Areal Research and Development, 33, 69-72.

[11] Negret, P.J., Di Marco, M., Sonter, L.J., et al.(2020) Effects of Spatial Autocorrelation and Sampling Design on Estimates of Protected Area Effectiveness. Conservation Biology, 34, 1452-1462. https://doi.org/10.1111/cobi.13522

[12] Portier, J., Gauthier, S., Robitaille, A., et al. (2018) Accounting for Spatial Autocorrelation Improves the Estimation of Climate, Physical Environment and Vegetation's Effects on Boreal Forest's Burn Rates. Landscape Ecology, 33, 19-34. https://doi.org/10.1007/s10980-017-0578-8

[13] Marasteanu, I.J. and Jaenicke, E.C. (2016) Hot Spots and Spatial Autocorrelation in Certified Organic Operations in the United States. Agricultural \& Resource Economics Review, 45, 485-521. https://doi.org/10.1017/age.2016.5

[14] Li, Y.T., Chen, Y.C. and Yan, W.Y. (2010) Spatial Structure and Evolution of Highway Accessibility in Henan Province. Areal Research and Development, 29, 60-64. 